\title{
OS DICIONÁRIOS JURÍDICOS BILÍNGÜES E O TRADUTOR - DOIS EM DIREITO CONTRATUAL
}

\section{Luciana Carvalho*}

\begin{abstract}
RESUMO: Este trabalho tem o objetivo de analisar e descrever a macro e a microestrutura dos dicionários jurídicos bilingües (inglês <> português) à disposição dos tradutores no mercado brasileiro até o início do ano de 2004. As obras analisadas são: o Compacto Dicionário Jurídico de Castro (1994), o Dicionário Jurídico de Noronha (1998) e o Dicionário Jurídico de Mello (1998). Esperamos atingir nosso objetivo examinando dois binômios encontrados em instrumentos contratuais, cuja escolha se deve aos desafios que representam para o tradutor. Nosso objetivo inclui, também, uma proposta de microestrutura de artigo para um dicionário jurídico destinado a profissionais da tradução que, muito mais que usarem dicionários técnicos para compreender o significado de um termo, voltam-se para eles em busca de elementos que lhes permitam produzir um texto. Tanto no estudo da microestrutura, quanto na proposta de artigo, faremos usos de ferramentas básicas de Lingüística de Corpus, procurando ilustrar como ela pode ser de grande valia nos campos da terminologia e da terminografia.
\end{abstract}

UNITERMOS: dicionários jurídicos; tradução jurídica; tradutor jurídico; Lingüística de Corpus; binômios

ABSTRACT: This paper aims at analyzing and describing the macro and microstructure of bilingual legal dictionaries (Portuguese <> English) easily available to translators in Brazil in 2004. The three titles are: Compacto Dicionário Jurídico (Castro, 1994), Dicioná-

\footnotetext{
* Mestranda em Estudos Lingüísticos e Literários em Inglês, subárea Tradução e Lingüística de Corpus na Universidade de São Paulo - USP. Bolsista CAPES. luciana_carvalho@hotmail.com
} 
rio Jurídico (Noronha, 1998) and Dicionário Jurídico (Mello, 1998). We hope to achieve this by examining two binomials found in legal agreements. Binomials represent a major challenge to the legal translator, thus the reason of our choosing them to illustrate this study. This paper also aims at proposing a structure for the entries of a legal dictionary designed to meet the needs of those who translate legal texts, seeing that translators not only need to understand a given legal term, but are required to produce legal texts. To achieve our goals when analyzing the microstructure of the dictionaries as well when proposing a structure for legal dictionary entries, we will make use of some of the basic tools in Corpus Linguistics seeing that today Corpus Linguistics is an invaluable tool in the field of terminology and terminography.

KEYWORDS: legal dictionaries; translation; legal translator; Corpus Linguistics; binomials

\section{Introdução}

Este artigo tem o objetivo de comparar, analisar e descrever a macroestrutura, microestrutura e o sistema de remissivas de dicionários ${ }^{1}$ jurídicos bilingües à disposição dos tradutores brasileiros que atuam na área técnica do direito valendo-se da combinação lingüística inglês e português. São eles: ${ }^{2}$ o Compacto dicionário juridico inglês/português, de autoria de Flávio de Castro, da editora Aide; o Dicionário juridico inglês/portuguêsportuguês/inglês de Durval de Noronha Goyos Jr., da editora

\footnotetext{
1 Não nos deteremos ao aspecto tipológico das obras (fato de receberem o nome de "dicionário"), pois isso implicaria um estudo exaustivo da terminologia pouco uniforme da questão da tipologia dos textos léxico-terminográficos. Uma das razões da falta de uniformidade é, para Haensch (1982), “(...) [el] uso arbitrario de estas denominaciones por parte de los distintos autores o casas editoriales y, hasta cierto punto, también, a modas de las distintas épocas" (Haensch, 1982 apud Barbosa, 1996). Assim, ao leitor que desejar informações acerca da tipologia dos textos lexicográficos, recomendamos o artigo "Dicionário, vocabulário, glossário: Concepções” de Barbosa (1996).

2 Para uma lista de todos os dicionários citados/usados nesse artigo, ver Anexo 1.
} 
Observador Legal, e o Dicionário jurídico português/inglês-inglês/ português de autoria de Maria Chaves de Mello, da editora Elfos.

Esperamos atingir nosso objetivo examinando dois binômios de direito contratual (null and void e wear and tear). A escolha dos binômios deve-se aos desafios que essas unidades representam para o tradutor (Mayoral Asensio, 2003).

Nosso objetivo inclui, também, uma proposta de modelo de microestrutura de artigo para dicionários jurídicos tendo em mente, como público-alvo, os tradutores que, muito mais que usarem dicionários técnicos para compreender o significado de um termo, voltam-se para eles em busca de elementos que lhes permita produzir um texto. O caminho entre compreender e produzir é um caminho árduo, principalmente em áreas técnicas em que os erros "(...) podem ter conseqüências graves para o processo de transmissão e aplicação de conhecimentos.” (Azenha, 1999). Infelizmente, o tradutor de textos jurídicos no Brasil conta com poucos recursos lexicográficos e terminográficos para desempenhar sua atividade com êxito e segurança.

Para fundamentação teórico-metodológica, partiremos do conceito de macro e microestrutura em Vilela (1995), dos modelos de microestrutura propostos por Barbosa (1989) e Krieger et al. (1998) e do conceito de remissiva em Bacellar (2002). O conceito de binômios adotado é o de Tagnin (1989), e a escolha da área de especialidade, a dos contratos, é justificada em Mayoral Asensio (2003). A importância da terminologia para a tradução é determinada por Cabré (1999). Além disso, faremos uso, na proposta de microestrutura e na avaliação dos dicionários jurídicos em tela, de ferramentas básicas da Lingüística de Corpus, tais como número de ocorrências, lista de palavras e lista de palavras-chave (Berber Sardinha, 2004). Ressaltaremos a importância da Lingüística de Corpus na tradução (Tagnin, 2002 e Atkins, 1996) bem como as necessidades do usuário de obras lexicográficas e terminográficas (Atkins, 1996).

Em um primeiro momento, abordaremos aspectos macroestruturais dos dicionários. Entendemos por macroestrutura "o conjunto das entradas e as partes complementares", como introdução, apêndices etc. (Vilela, 1995). As partes complementares são responsáveis pela informação do usuário, possibilitando 
que ele identifique suas necessidades de acordo com os recursos fornecidos; por outro lado, um conjunto de verbetes ordenados possibilita a leitura vertical da obra.

A macroestrutura de uma obra de especialidade difere bastante da de uma obra de língua. Enquanto no Dicionário Aurélio, por exemplo, encontramos 24 acepções para "ação" (hiperônimo) dentro de uma mesma entrada. Em uma obra visando refletir apenas a área jurídica, encontraríamos diversas entradas com cada uma das acepções (hipônimos). Isso deveria ocorrer porque "ação", dentro da área de especialidade, terá muitas acepções, cada uma com função específica dentro do referido discurso. Outrossim, um maior número de entradas facilita a consulta.

Para ilustrar o que acabamos de afirmar, abaixo exemplos de trecho do verbete "ação" no Aurélio e em Noronha. O primeiro, exemplo de obra lexicográfica e o outro, de obra terminográfica.

açăo. [5o lat, octione.] S. $f$. 1. Ato ou efeito de agir, de atuar; atuaça, ato, feito, obra. 2. Manifestaçào de uma força, de uma energia, de un agente. 3. Naneira como um corpo, wn agente, atua sobre outmo: efeito: acâ do tempo; apieg de um medicamenta. A. Capacidade de mover.se, de agix: Ao ser-ihe apontada o reviblver, $f$ cor sem acto. 5. Miovimento, funcionamento; laor sm acroo motor do carro. 6. Modo de proceder; comporta mento, atitude. Sol acāo é indigna de pessoa decente. 7. Exercicio da forca, do poder de fazer alguma coisa G. "cidade méríco-militar brotada por um milagre de açào ern meses no deserto dum areal" (Ricardo Jorge, Canhentho dum Vagamundo, p. 3), 8. Influẹncia (sobre alguém ou alguma coisa): .t. "nos primeiros anos de moco parecia [Machacto de Assis] conflar na acão da sua vontade e na continuidade do trabalho." (Mário de Alencar, em Machadio de Assis, Teutro, p. 10). 9. Ocor. réncia, acuntecimento, sucesso. 10. Solenidade, cerimònis 11. Sequéncia de acontecirnentos thuma peca teatral dum flime, dum romance, etc; enredo, intriga, rama. 12. Cin. Telev. O ato de filmar. 13, Eeon Parce la em que se divide o canital de uma sociedade anónimar 17 "A companhia ou sociedade anònima terá o man dividido em açōes ..." (Lei das Sociedades Anón nimas, Let n. G.A01 de 35.12.1976, Art. 19). 14. Econ Gocumento negociável representativo da proprtedade de tal parcela: it Ele herdou de seu tio mutas scies do Ban tal parasil 15. E. Ling. No verbo e no substantivo expressăo de processo ou atividade. 16. Et. Atividade responsável de um sutjeita; realizaçäs de una vontade gue se presume livre e consciente. [C1., nesta aceps., ato (6) e liberdade (11).] 17. Filos. Processo que decorre di natureza ou da vontade de um ser, D agente, e de que resulta criaçăo ou modinicaçầo da realidade. [Cf. nesta acepc., ato (8).] 18. Filos. O curso desse processo; ativi
dacte. 19. Filos. Resultado ou efeito desse processo. 20 açâo- action at law; lawsuit; suit; claim; judicial proceeding: legal action; case; cause. ação - share; stock.

ação acessória - ancillary suit or action; accessory action.

ação acidental - incidental proceeding.

ação administrativa - administrative case.

ação ajuizada - case filed; lawsuit.

ação anulatória - action for annulment.

ação ao portador - bearer share.

ação beneficiária - founder's shares.

ação caucionável - bailable action.

ação cautelar-interlocutory injuction; injuction. ação civil - civil action; civil suit.

ação coletiva - class action.

ação com direito a voto - voting share.

ação cominatória - perpetual injunction.

ação comum - ordinary share. ação confessória - action for enforcing an
easement.

ação constitutiva - constitutive action.

açẫo continuada - case continued.

ação contra a coisa - action in rem.

ação contrária - action of agent against principal.

Em um segundo momento, abordaremos apenas aspectos microestruturais tomando por exemplo dois binômios: wear and tear e null and void. 
Entendemos por microestrutura o conjunto de informações fornecidas de forma ordenada em um verbete. Nas palavras de Vilela (1995: 78) microestrutura é "a entrada e o tratamento dado a essa entrada através da rede de relações definicionais, relações gramaticais, relações semânticas (como sinonímia, antonímia, polissemia, etc.) e relações pragmáticas (área de uso, freqüência, niveis de língua, etc.)". Dependendo do objetivo da obra lexicográfica ou terminográfica, essas informações podem ser de vários tipos. Assim, uma obra que trate as unidades lexicais no nível do sistema, como o Dicionário Aurélio (vide figura acima à esquerda), por exemplo, fornecerá todos os semas daquele lexema na língua geral. Já as obras como as analisadas aqui, que tratam da norma, deverão incluir informações específicas da área de especialidade. Uma característica importante da microestrutura é ser uma "estrutura constante, correspondente a um código aplicável a qualquer entrada" (Barbosa, 1989).

Barbosa (1989) propõe um modelo de microestrutura de verbete compreendendo uma entrada mais um enunciado lexicográfico, que, por sua vez, contém um paradigma informacional (PI), um paradigma definicional (PD) e um paradigma pragmático (PP). Sintetizamos o modelo no esquema abaixo em que o verbete é igual a:

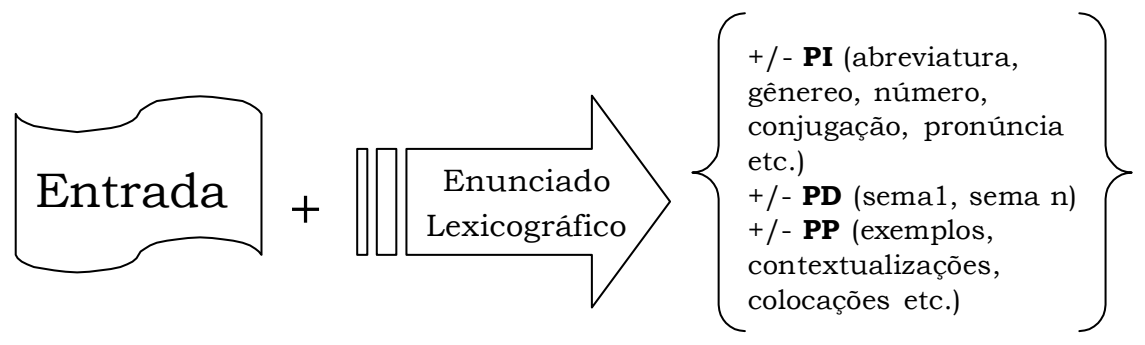

O modelo em Barbosa não foi concebido para obras bilíngües, pois não há um paradigma de forma equivalente. Assim, em busca de um modelo que contivesse o paradigma de forma equivalente (PFE), identificamos o código dos verbetes (microestrutura) na obra terminográfica trilingüe intitulada Dicionário de Direito Ambiental - Terminologia das leis do meio ambiente, de Krieger et al. O modelo de verbete adotado na obra está sintetizado na próxima figura: 


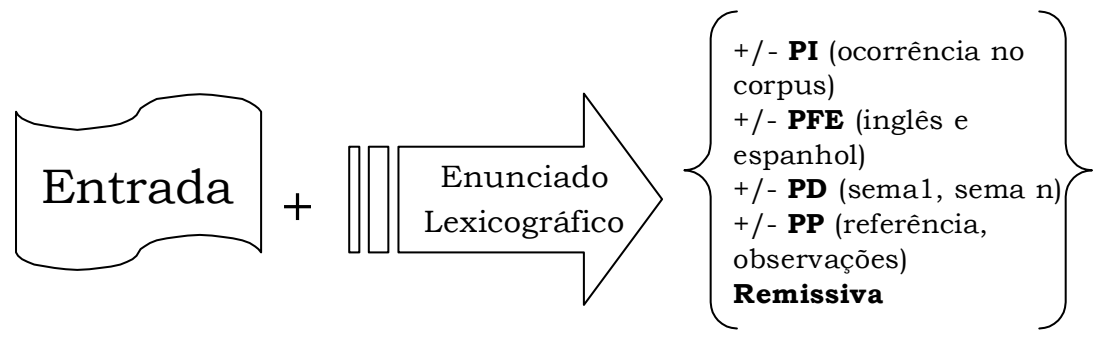

Após observar os dois modelos de microestrutura, faz-se mister ressaltar com as palavras de Barbosa (1989) que "Se, por um lado, a microestrutura, considerada em todos os seus aspectos, é variável de uma obra lexicográfica para outra, é, por outro lado, constante no interior de uma mesma obra; uma vez adotado um programa, sustentar-se-á ao longo de uma mesma obra". Com isso em mente, veremos em momento oportuno se as microestruturas escolhidas pelos autores que examinamos estão de acordo com essa conclusão.

Acerca das remissivas, podemos dizer que são as relações que mantêm a coerência semântica entre os termos (Fromm, 2003), corrigindo o isolamento das mensagens no nível da microestrutura (Bacellar, 2002 apud Fromm, 2003). São identificadas por abreviaturas, tais como, $C f$. e $v$.

Em relação à escolha da área jurídica, mais especificamente, a do ramo do direito dos contratos, ${ }^{3}$ ela decorre do fato de que os contratos estão entre os documentos mais dificeis de traduzir (e de ler) (Mayoral Asensio, 2003) e que isso se deve a vários fatores, ainda segundo o autor, entre os quais, a existência de binômios e trinômios. Segundo Mayoral Asensio, em virtude dos binômios e trinômios a compreensão, que é parte do trabalho do tradutor, é prejudicada, e a tentação de traduzir literalmente as palavras no original é grande. $\mathrm{O}$ autor ainda afirma que traduzir o sentido individual das palavras de acordo com um dicionário produz nonsense, pois sua tradução é impossivel (2003). O autor conclui que há um risco de tornar a tradução incompreensivel, já que o estilo da lingua-fonte raramente é o mesmo da língua-alvo, e a melhor saida seria traduzir usando

3 Ver arborescência da área do Direito Contratual no Anexo II. 
equivalentes funcionais (functional equivalents) (Mayoral Asensio, 2003) dentro de um mesmo tipo de texto. Em suma, a busca de correspondentes "seguros" é árdua; em virtude da tecnicidade da área jurídica, é agravada quando se trata de binômios.

Segundo Tagnin (1989), "Um binômio é geralmente formado por duas palavras pertencentes à mesma categoria gramatical e ligadas por uma conjunção ou preposição". Além disso, afirma a autora na mesma obra que: "Podemos caracterizar os binômios de acordo com dois aspectos sintáticos e um semântico". São eles:

(a) a combinabilidade - "é necessário que a combinação de seus elementos tenha sido convencionalizada, que esses elementos usualmente 'andem juntos' ";

(b) a ordem - pode ser consagrada ou não;

(c) a idiomaticidade - podem ser idiomáticos ou não.

Ao contrário do que ocorre na linguagem coloquial, em que a presença e o uso de binômios e polinômios é uma opção do usuário (e.g. o falante que desconhece o binômio time and again se sairia muito bem se usasse frequently, quite often etc., conforme o contexto), na linguagem jurídica, os binômios / polinômios são exigências da própria área, principalmente quando se trata do direito dos contratos. Convém dizer que as situações de comunicação em que os binômios aparecem como termos "são essencialmente situações especializadas restringidas pragmaticamente pelas características dos interlocutores (principalmente o emissor), da temática que se transmite, da função que se almeja com a transferência e das situações de comunicação" (Cabré, 1999).

Portanto, a obrigatoriedade ou não do emprego de binômios e polinômios decorre da tecnicidade dos termos, de seu significado dentro do discurso. O falante que os desconhece, muito provavelmente, poderia deixar de expressar exatamente o que deseja. Por exemplo, um falante que produzisse null and invalid (que não é binômio em inglês) por desconhecer o binômio null and void, certamente teria problemas se do contrato do qual constasse a primeira expressão decorresse algum litígio que de- 
pendesse de interpretação judicial. O órgão julgador, por exemplo, teria dificuldades em encontrar o que a parte quis dizer com null and invalid e, provavelmente, buscaria o significado dos termos null e invalid isoladamente, dada a estranheza da combinação. Por outro lado, null and void seria tratada como unidade de significado.

Para ilustrar a ausência de tratamento dado a binômios nos dicionários técnicos bilíngües existentes no Brasil e de uso corrente por tradutores profissionais, analisamos as letras A, B e $C^{4}$ do dicionário de Mello (1998). Nelas encontramos apenas 8 binômios/polinômios, dos quais:

(a) 3 mereceram o mesmo verbete $(C \& F, C F$ e cost and freight);

(b) apenas 2 possuem correspondentes satisfatórios (checks and balances e cost and freight);

(c) e nenhum apresenta o contexto em que é empregado.

Esses resultados sugerem que as obras à disposição do público brasileiro não consideram os binômios unidades terminológicas, apesar de abundarem em muitas esferas do discurso jurídico, não podendo os tradutores deixar que passem despercebidos (Mayoral Asensio, 2003: 98).

Nosso interesse pelos profissionais da tradução decorre do fato de fazermos parte da comunidade, bem como de atuarmos na área da tradução jurídica e, portanto, de experienciarmos, no dia-a-dia, as limitações dos recursos lexicográficos e, principalmente, terminográficos disponíveis.

Cabré (1999) ressalta a importância da terminologia para a tradução especializada em três pontos dos quais dois nos interessam em particular: primeiro, os termos concentram a maior densidade de conhecimento especializado no texto; e, segundo, a qualidade de uma tradução especializada está diretamente relacionada ao uso da terminologia (não de paráfrase) adequada ao nivel de especialização e que seja realmente empregada pelos usuários naturais. Assim, como não-especialista, o tradutor es-

4 Anexo III. 
pera encontrar obras terminológicas/terminográficas que satisfaçam suas necessidades. A importância de tais obras, do ponto de vista da tradução, ocorre em virtude de os tradutores se apoiarem nelas para "expressar o conhecimento especializado com adequação" (Cabré, 1999). A mesma autora (1999) afirma que: "A terminologia é a base da comunicação entre os especialistas e o tradutor especializado, na condição de mediador, torna-se de fato uma espécie de especialista e assim deve agir ao selecionar os termos." Todavia, veremos a seguir que as obras "terminográficas" analisadas aqui muitas das vezes acabam por dificultar a seleção dos termos pelo tradutor, truncando as informações apresentadas (ora insuficientes, ora inadequadas) e impedindo que ocorra a comunicação técnica. Pretendemos, por tudo isso, que nossa proposta de modelo de microestrutura, elaborado para os profissionais da tradução, concorra para que essa situação seja revertida.

Veremos também que o fim almejado pelo tradutor, o de expressar o conhecimento técnico especializado objeto da terminologia, pode ser mais facilmente atingido quando as obras terminográficas fazem uso, ainda que parcialmente, da Lingüística de Corpus (conforme procuraremos fazer em nosso modelo de microestrutura).

A Lingüística de Corpus pode ser empregada em várias áreas do conhecimento, tais como na lexicografia (e.g. na elaboração de dicionários), na terminologia (e.g. na elaboração de vocabulários), na tradução (e.g. na determinação das colocações de uma palavra), no ensino de línguas (e.g. na criação de exercícios de vocabulário, gramática etc.), na literatura (e.g. em estudos contrastivos), na análise do discurso (e.g. em microestrutura), entre outras. Por meio da compilação de textos representativos de uma lingua e de uma determinada área de especialidade (corpora técnicos), processados por programa de computador (e.g. WordSmith Tools, Stablex etc.), e do uso de inúmeras ferramentas, muitas das quais se valem de análises estatísticas, o pesquisador é capaz de chegar a conclusões várias, tais como constatações sobre o uso de certos termos ou palavras (por meio da análise das linhas de concordância obtidas com a ferramenta "Concord" no caso do WordSmith Tools, por exemplo); a identificação das co- 
locações usadas com certos termos/palavras (com a ferramenta "Collocates" no WordSmith Tools); a identificação de fraseologia de um determinado corpus (com a ferramenta "Clusters" no WordSmith Tools) etc. As principais ferramentas do WordSmith Tools mencionadas neste artigo ("concordanceador", lista de palavras e palavras-chave) são abordadas exaustivamente em Berber Sardinha (2004) e aqui serão usadas apenas perfunctoriamente. A WordList "propicia a criação de listas de palavras" que permitem ao usuário identificar as palavras no corpus por ordem de freqüência ou por ordem alfabética (Berber Sardinha, 2004). Trata-se de uma ferramenta que, na elaboração de obras lexicográficas /terminográficas, pode ser usada para decidir quais as palavras que mais ocorrem e que, portanto, não podem deixar de constar em determinada obra. A ferramenta Concord, por sua vez, "produz concordâncias ou listagens das ocorrências de um item específico (chamado palavra de busca ou nódulo, que pode ser formado por uma ou mais palavras) que vem acompanhado do texto ao seu redor (o cotexto)" (Berber Sardinha, 2004). Esta ferramenta permite que o usuário extraia exemplos do termo em seu "habitat natural", auxiliando-o a determinar em que situações o referido termo é empregado. A ferramenta KeyWords (palavras-chave) otimiza a WordList. Esta ferramenta gera uma "lista de palavras por meio da comparação de suas freqüências com uma lista de referências" (Berber Sardinha, 2004) e, assim, permite determinar não apenas as palavras que mais ocorrem, mas as palavras realmente peculiares a uma área de especialidade. Além das ferramentas do WordSmith Tools, usaremos também o mecanismo de busca na internet, o Google, ${ }^{5}$ para auxiliar na determinação da ocorrência e do contexto dos termos analisados.

Em relação à tradução, o emprego da Lingüística de Corpus permite que, por meio de ferramentas muito simples, tais como as linhas de concordância, o tradutor observe a linguagem que ocorre naturalmente e se livre da pecha de "ingênuo" (Fillmore apud Tagnin, 2002) que "pode transparecer tanto na sua habilidade de compreensão, quanto na de produção" (Tagnin, 2002).

5 www.google.com 
A Lingüística de Corpus permite que o tradutor chegue a soluções naturais, e "os corpora (...) têm muito mais, do que possa parecer, a oferecer aos tradutores. Os corpora não apenas mostram como determinada palavra ou expressão é usada, mas também permitem que o usuário reflita sobre o processo e a natureza da tradução." (Hunston apud Berber Sardinha, 2002: 15).

Em relação à terminografia/lexicografia, permite que o pesquisador extraia termos que realmente interessam a uma determinada obra, examine cada termo em muitos contextos ao mesmo tempo, determine a fraseologia envolvida, bem como extraia exemplos do uso, entre muitas outras coisas que aqui não nos cabe examinar.

Em matéria de dicionários, a Lingüística de Corpus ainda não é aproveitada ao máximo (Tagnin, 2002 e Atkins, 1996). Os poucos dicionários elaborados sob a luz da Lingüística de Corpus "oferecem uma lista restrita de ocorrências" (Tagnin, 2002 e Atkins, 1996), e "o quadro é agravado quando se trata de dicionários bilíngües” (Tagnin, 2002).

Atkins (1996) e Varantola (apud Atkins, 1996) verificaram que, após consultarem um dicionário bilíngüe, os usuários muitas vezes consultam um dicionário monolíngüe e concluem que o dicionário ideal deveria oferecer funções de dicionário monolíngüe para os usuários bilingües (definições, etimologia, notas sobre o uso). Ao elaborar nossa pesquisa, certos campos de nosso modelo de microestrutura foram escolhidos com isso em mente. Além disso, constatam que os dicionários multilingües tendem a ser meras listas de palavras em várias linguas (Atkins, 1996).

\section{A macroestrutura dos dicionários jurídicos bilingües}

A seguir, descreveremos, na ordem em que foram mencionados, os dicionários jurídicos bilingües, na combinação lingüística inglês - português, à disposição do público brasileiro. Não julgamos necessário analisar as versões mais recentes das referidas obras, pois, ao examiná-las, constatamos que não houve 
mudanças substanciais entre as edições que possuímos e as últimas. ${ }^{6}$ Além disso, nosso estudo da obra não pretende ser exaustivo, mas apenas chamar a atenção para um pequeno número de aspectos macro e microestruturais de obras dessa natureza sem, contudo, esgotá-los.

O Compacto dicionário jurídico inglês-português, do advogado Flávio de Castro, foi editado pela editora Aide em 1994. Possui, de acordo com a própria capa, cerca de " 1.500 termos e expressões inglesas da linguagem forense com as respectivas traduções". Na orelha, há uma afirmação de que a obra é direcionada a "leitores, militantes e estudantes". Não há uma apresentação da obra, mas uma "Nota" em que o autor menciona ter sido feita para o "profissional e...o estudante de direito" e que visa conter, "tão-somente aqueles termos e expressões de uso corriqueiro no inglês forense". Ainda na "Nota", o autor afirma que "evitamos mostrar outros sinônimos que, também, cabiam e, também conhecíamos, mas não apresentavam utilidade para nosso fim". Além disso, há uma outra afirmação interessante: “...algumas das vezes, optamos por não traduzir o termo ou a expressão, oferecendo diretamente a figura jurídica equivalente em nosso direito". Por fim, na ausência de referências bibliográficas, o autor destaca, ainda na "Nota", apenas duas fontes de consulta, quais sejam, o Black's Law Dictionary e o Dicionário jurídico inglês-espanhol de Guillermo Cabanellas, justificando, com a menção dessas duas obras, que o trabalho está "mais voltado para o Direito americano".

Nesse primeiro exame, existe uma leve incoerência entre a afirmação de que as "expressões são inglesas" e que o trabalho é "voltado para o Direito americano". Mais adequado seria dizer que as expressões aparecem "em inglês". Verificamos que a obra de Castro justifica a escolha das expressões por serem as "de uso corriqueiro no inglês forense", mas não revela como as determinou. A falta de menção a um corpus em que as expressões ocorrem macula a cientificidade e o rigor da obra. Nesse sentido, Borba (2003) afirma que "uma primeira delimitação [de obra le-

\footnotetext{
6 Edições aumentadas dos dicionários Noronha e Mello foram lançadas em 2006.
} 
xicográfica] estaria na ocorrência dessas palavras" em determinado corpus de estudo. Isso seria perfeitamente sanado em uma pesquisa baseada em corpus em que o autor, após compilar seu corpus jurídico, procederia a uma extração dos termos mais freqüentes e dos termos-chave. Para tanto, temos programas como o WordSmith Tools ${ }^{7}$ e o Stablex, ${ }^{8}$ que permitem que isso seja feito em segundos, determinando, assim com precisão as verdadeiras expressões mais freqüentes, ou melhor, "de uso corriqueiro no inglês forense".

Um outro dado preocupante é ter o autor mencionado que “... algumas das vezes, optamos por não traduzir o termo ou a expressão, oferecendo diretamente a figura jurídica equivalente em nosso direito". Isso reflete uma falta de uniformidade no tratamento dos termos, bem como nos leva a crer que, para o autor, "tradução" é apenas a literal, que, como sabemos, deve ser evitada também na tradução técnica (Mayoral Asensio, 2003). A falta de uniformidade no tratamento dos termos (microestrutura) é confirmada pela figura abaixo em que as primeiras duas entradas contam com um paradigma definicional, as três últimas com paradigma de forma equivalente.

OFFER OF JUDGMENT

Acordo entre as partes para encerramento da causa após o início do processo.

OMBUDSMAN

Autoridade pública que tem por atribuição ouvir queixas da população contra atos das próprias autoridades.

OPEN A CASE

Iniciar um processo judicial.

OPEN A COURT

Abrir a audiência ou o julgamento.

OPEN A JUDGMENT

Ação rescisória.

A segunda obra, o Dicionário jurídico português-inglês inglês-português, $7^{\mathrm{a}}$ edição, da também advogada Maria Chaves

\footnotetext{
7 De autoria de Mike Scott, da Universidade de Liverpool.

8 De autoria de André Camlong, da Universidade de Toulouse.
} 
de Mello, editado pela editora Elfos em 1998, ao contrário da primeira obra mencionada, é bidirecional. O dicionário deve contar com, aproximadamente, 8.500 verbetes em cada direção; todavia, esta informação não consta do dicionário. Os verbetes estão organizados em ordem alfabética, e as entradas estão todas em caixa-alta (ver próxima figura).

Em "Ao leitor", a autora afirma que a obra "tem efetivamente atendido à sua finalidade". Entretanto, não encontramos especificações na obra referentes ao objetivo nem ao públicoalvo, salvo de forma indireta, como poderemos constatar da afirmação que faz a autora acerca dos paradigmas de forma equivalente. A autora alerta "para o fato de que uma tradução, por mais aprimorada que seja, não passa de uma imitação do texto traduzido, dificuldade no caso somada à temeridade de definir termos jurídicos, ainda mais de forma que possa ser entendida também pelo público leigo", ou seja, parece-nos que a autora visa atender também ao público leigo. Infelizmente, não é essa a melhor técnica para uma obra terminográfica, pois, nas palavras de Aubert (1996), "A comunidade de usuários das linguagens de especialidade, tanto quanto a comunidade e a lingua em geral, não constituem um todo uniforme, mas se subdivide em grupos variados, com necessidades, pressupostos e motivações também variados (por exemplo, o engenheiro de projetos, o operário, o publicitário, o distribuidor, o mecânico da assistência técnica, o consumidor)." O mesmo vale para o advogado, o estudante e o leitor comum. Nesse sentido, só será possivel estabelecer o conteúdo de uma obra após delimitar com cuidado seu público-alvo, para que, num segundo momento, seja possivel passar "à seleção e ao arranjo dos elementos descritivos que deverão figurar nos verbetes. Tal seleção está relacionada com o objetivo específico do dicionário.” (Borba, 2003). Uma reflexão anterior sobre seu público evitaria que a autora incluísse na macroestrutura verbetes como os abaixo, em que pelo menos os dois primeiros não são da área de especialidade e o último (narr and cognovit) não apresenta nenhuma ocorrência no Google, o que indica, inicialmente, não ser um termo de uso corrente. Isso vai de encontro à afirmação de Barbosa, segundo a qual “(...) os vocabulários técnico-científicos situam-se numa perspectiva 
sincrônica (eventualmente diacrônica), não lhes sendo pertinentes as variações diatópicas e diastráticas (ressalvados os casos caracterizados como fenômenos de socioterminologia); definemse, contudo, por uma rigorosa perspectiva sinfásica, própria de um tecnoleto, representativa de um universo de discurso (...)" (1996). Assim, se está em desuso, por exemplo, não deveria constar de uma obra que se propõe atual. Todavia, encontramos o termo em Black, mas no verbete narr and cognovit law, cuja definição ${ }^{9}$ difere da apresentada em Mello.

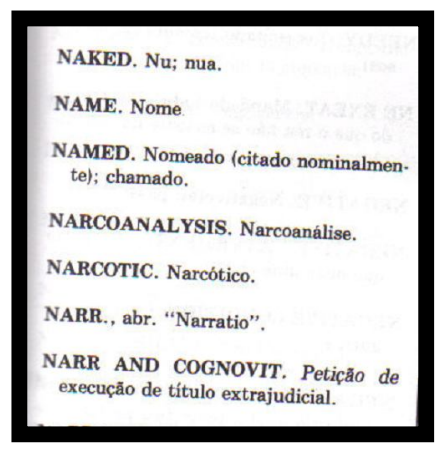

Na página seguinte, há uma lista das 7 abreviaturas usadas na obra (abr. abreviatura; adj. adjetivo; ING Inglaterra; L latim; q.v. vide o verbete; SIN sinômimo-alternativa e v. verbo). Apesar de a autora ter selecionado algumas abreviaturas, faz pouquíssimo uso delas na microestrutura (paradigma informacional) dos verbetes, como podemos observar no exemplo abaixo. No mesmo exemplo, constatamos a mesma falta de uniformidade que acusamos em Castro, ou seja, os verbetes por vezes possuem paradigmas definicionais (ver nul tiel record) e, por outras, paradigmas de forma equivalente (ver null and void). Além

9 Narr and cognovit law. Law providing that judgment may be had for plaintiff on notes by confession of an attorney that amount shown on notes, together with interest and costs, constitutes legal and just claim; word "narr" being an abbreviation of Latin word "narratio," meaning complaint or petition, and word "cognovit" meaning that defendant has confessed judgment and justice of claim. Dyer v. Johnson, Tex.Civ.App., 19 S.W.2d 421, 422. See Judgement (Confession of Judgment). (Black's Legal Dictionary) 
disso, constata-se uma ausência de um sistema de remissivas nas obras até agora examinadas.

NUL. Prefixo de negação.

NUL TIEL. Não existe; não há.

NUL TIEL RECORD. Sentença que declara a inexistência do título ou documento alegado.

NULL. Nulo; ineficaz; inexistente.

NULL AND VOID. Nulo e sem efeitos.

NULLIFICATION. Anulação.

NULLITY. Nulidade; inexistência.

No índice, duas inserções curiosas a que a autora chama de "Lista Suplementar de Termos e Expressões Jurídicas" (páginas 499-512) e "Supplementary List of Legal Words, Terms and Phrases" (páginas 513-520) estão ao final da obra. Há mesmo uma chamada para as referidas listas na capa. Entretanto, observamos que as entradas de uma não correspondem às da outra, ou seja, são duas listas diferentes em direções diferentes, ambas unidirecionais: uma português $>$ inglês e a outra inglês >português. A presença de tais listas não é justificada em nenhuma parte da obra, e há termos que constam tanto da parte principal da obra, quanto da referida lista, mas com enunciados lexicográficos completamente diferentes. É o caso do termo abaixo, respectivamente:

Ainda acerca da macroestrutura do dicionário de Mello, salta aos olhos a falta de uniformidade no tratamento das entradas. A autora não deixa claro por que, em "ação", optou por fazer entradas diferentes para cada tipo de ação, enquanto em 
"interpretação" incluiu todos os tipos de interpretação dentro do mesmo verbete (ver exemplos abaixo).

INTERPRETAÇĀO. interpretation (processo pelo qual se procura descobrir e expor o verdadeiro sentido de uma lei ou outro instrumento escrito).

« autêntica. authentic interpretation.

" ampliativa. extensive interpretation.

" ao pé da letra. close interpretation.

" extensiva. extensive interpretation.

" lógica. logical interpretation.

" restritiva. restrictive interpretation.

" legal. legal interpretation.

" doutrinária. doctrinal interpretation.

« gramatical. close interpretation.

« usual. judicial interpretation.

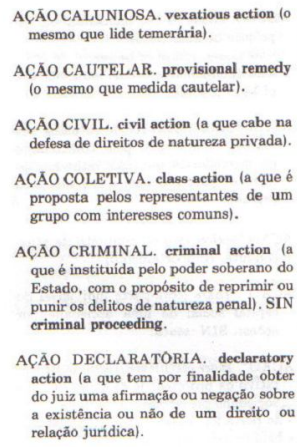

AC̣ÃO CIVIL, eivil action (a que cabe na defesa de direitos de natureza privada).

AÇÁ COLETTVA. class action la que é proposta pelos representantes de um grupo com interesses comuns).

AÇÃO CRIMINAL. criminal action (a que é instituída pelo poder soberano do Estado, com o propósito de reprimir ou
punir os delitos de natureza penal). SIN criminal proceeding.

AÇĀO DECLARATÓRIA. declaratory action (a que tem por finalidade obter do juiz uma afirmaçåo ou negaçáo sobre a existência ou năo de um direito ou relação jurídica).

AÇĀO DE CONSIGNAÇÃO EM PAGA

Por fim, a autora cita a bibliografia, nas páginas 521 e 522 , da qual constam apenas 39 títulos, dos quais por sua vez 14 são outras obras lexicográficas. Além disso, as demais não estão distribuídas entre os vários ramos do direito, o que sugere uma falta de critérios na constituição do corpus. A importância de um corpus é a de definir a obra, devendo ser exaustivo em linguagem técnica e devendo obedecer a critérios específicos (Rivera Dominguez, 1985 apud Barbosa, 1996). Caso contrário, certas áreas serão preteridas em detrimento de outras. Em uma obra que visa abranger toda a área do direito, como é o caso das obras nesse estudo, isso não poderia passar despercebido.

A última obra analisada é o Dicionário jurídico inglês-português português-inglês, da editora Observador Legal, de Durval de Noronha Goyos Jr. A edição que examinamos foi a 3. a , de 1998. Assim como em Mello, é também uma obra que propõe ser bidirecional. Ao contrário da obra de Mello, a primeira parte é inglês-português, e não português-inglês. Nas páginas i, ii e iii, a obra traz informações sobre a carreira de advogado internacional do autor, bem como sobre a atuação do Escritório Noronha. Uma detalhada biografia do autor também consta do dicionário (p. 569, 571 e 572). Vemos que se dá amplo destaque à formação jurídica do autor sem, contudo, mencionar sua experiência nas áreas da terminografia e da lexicografia. 
$\mathrm{Na}$ "Introdução à terceira edição" é possivel determinar, ainda que indiretamente, o público a que a obra visa atender e seu objetivo, quais sejam, "profissionais legais e empresários no tocante às relações comerciais internacionais" em "negócios com países de língua portuguesa e inglesa".

Diferentemente das obras supramencionadas, toda informação dada é bilíngüe, desde o índice e as introduções às edições passadas, à informação sobre o autor ao final. Na "Introdução à terceira edição" a editora informa que o dicionário conta com aproximadamente 40 mil verbetes. Entretanto, entre esse expressivo número de verbetes, encontramos palavras que não pertencem à área de especialidade. Isso sugere que não houve uma preocupação em coletar um corpus especializado e dele extrair uma lista de palavras (WordList) e com essa lista determinar quais as palavras que realmente pertencem ao discurso jurídico (KeyWord List). Mesmo que o autor não optasse (como não optou) por fazer uso da Lingüística de Corpus, não seria dificil identificar certos termos que são totalmente incompatíveis com o domínio em questão e que não deveriam ser inseridos em uma obra dessa natureza apenas para efeito quantitativo.

O exemplo abaixo ilustra o que constatamos. Dentre os 19 verbetes selecionados, pelo menos 10, ou mais, (wealthy, wear, weary, weather, weather forecast, web, week, weekly, weep, weight, weighed) não são termos técnicos em direito, nem sequer palavras de alta freqüência no domínio e, portanto, não deveriam constar de uma obra dessa natureza. Nesse sentido, Barbosa (1996) afirma que "o vocabulário técnico-científico/especializado deve recuperar, armazenar vocábulos de um universo de discurso (...)". Tal fato poderia ser facilmente corrigido com o emprego da ferramenta KeyWords do WordSmith Tools, que recuperaria apenas os termos característicos da área de especialidade em questão (Berber Sardinha, 2004). 


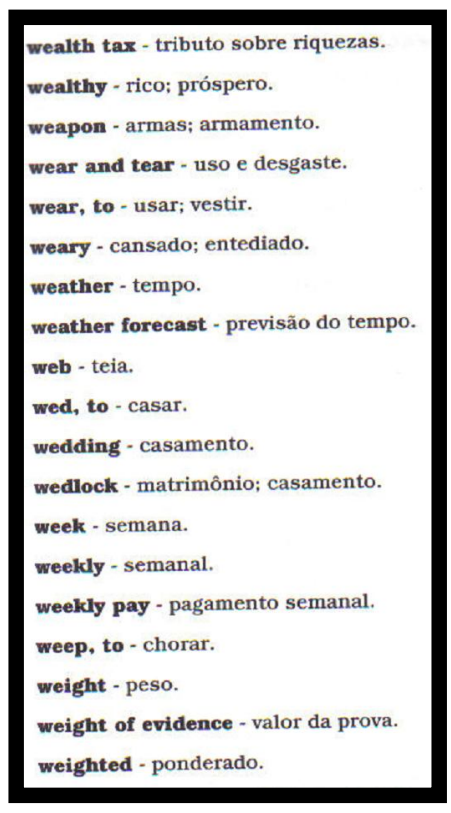

Outra característica dessa obra é que há uma seção intitulada "How to use the Noronha Legal Dictionary, by the author - Como usar o dicionário Noronha, pelo autor" nas páginas xxi e xxiv, respectivamente. É esta seção que fará com que nos detenhamos mais na descrição dessa obra, comparando-a às descrições das duas anteriores e permitindo-nos abordar também alguns aspectos microestruturais. Interessantemente, esta seção, consoante a "Introdução à segunda edição" não constava da primeira. A referida seção, na subseção "Introdução", informa que os "verbetes" estão em negrito, fato que não constatamos. São as "entradas" que estão formatadas desse modo, demonstrando falta de precisão terminológica. Ainda na subseção, o autor menciona as áreas técnicas envolvidas: negócios em geral, contabilidade, operações bancárias e finanças, tributação; seguros, comércio internacional; meio ambiente e a "terminologia jurídica mais estrita”. Entretanto, não é possivel constatar um corpus que compreenda todas as áreas mencionadas pelo autor, pois não há referência à bibliografia consultada.

A terceira subseção, intitulada "Natureza dos verbetes", afirma que se trata de um "dicionário dos advogados militan- 
tes", justificando que "os verbetes possuem uma natureza prática e empenham-se em apresentar opções para a tradução técnica mais precisa para a outra língua". O autor vai mais longe e afirma que, "como este é um dicionário jurídico bilíngüe, o autor não se esforçou, por via de regra, em explicar todos os preceitos jurídicos envolvidos, mas somente fornecer a opção de tradução mais precisa possivel para a outra língua" e orienta "o leitor que se interessar a respeito de particularidades adicionais daqueles preceitos deve, então, pesquisar a fonte jurídica apropriada na sua jurisdição". Entretanto, a macroestrutura adotada não condiz com tal afirmação, pois ao observarmos a figura anterior, veremos que muitos dos "termos" não possuem "natureza prática", já que não pertencem à esfera do Direito.

O autor afirma também que "certos termos específicos, em vista do seu alto grau de especialização, fizeram jus a uma explicação em seguida à respectiva tradução". Com isso, mesmo antes de examinarmos a microestrutura dos verbetes, é possivel antecipar uma falta de uniformidade, ou seja, da existência de um código único para toda a obra. É o que constatamos no exemplo abaixo, em que os $1 .^{\circ}, 3 .^{\circ}, 5 .^{\circ}$ e $6 .^{\circ}$ verbetes possuem paradigma de forma equivalente, ao passo que o $2 .^{\circ}$ e $4 .^{\circ}$, paradigma definicional. Na realidade, o $2 .^{\circ}$ e o $3 .^{\circ}$ verbetes possuem a mesma entrada, cujo enunciado lexicográfico, por sua vez, possui paradigmas diferentes: definicional no primeiro e de forma equivalente no segundo.

mispleading - petição inepta.

misprision - omissão na prevensão de um crime ou notificação das autoridades sobre a ocorrência de um crime; desacato.

misprision - negligência.

misrepresentation - declaração falsa semelhante à falsidade ideológica, mas não inclui a omissão de fato-x

missed discount - descontos perdidos.

missing - faltante.

O autor alerta para o fato de que "as traduções e/ou definições serão dados em português do Brasil e inglês dos Estados Unidos da América, todavia, ocasionalmente, as versões do Rei- 
no Unido ou de Portugal também serão indicadas", além disso "sempre que palavras nas versões brasileiras e lusitanas do português ou nas versões do Reino Unido e dos Estados Unidos da América do inglês tiverem significados diferentes, o dicionário apresenta verbetes separados". Isso faz com que encontremos verbetes como: "trabalho nocturno" $(\mathrm{P})$ - night job, mas não "trabalho noturno". Para nossa surpresa, também não registramos o verbete para night job, o que nos leva a crer não se tratar de um dicionário verdadeiramente bidirecional.

Há uma subseção de nome "Termos de outras línguas", e o autor explica que "há expressões ou palavras de outras linguas que são usadas não traduzidas". Entretanto, o autor dá a tradução, por exemplo, na direção inglês > português temos consiglieri (I) - conselheiro e, na direção português > inglês, boleta (E) ticket. Consultando "conselheiro" no dicionário, obtivemos "adviser; counsellor". Assim, consiglieri não consta no enunciado lexicográfico do verbete de "conselheiro".

O mesmo ocorre com ticket, entrada na qual boleta não aparece. Para ticket, obtivemos "bilhete; entrada; passagem; passe; etiqueta; rótulo; chapa de candidato". Trata-se de mais um indicativo de que o dicionário não é, propriamente, bidirecional, já que os verbetes na seção português/inglês não correspondem aos verbetes na seção inglês / português.

A sétima subseção, "Falsos cognatos", indica que o dicionário "empenhou-se em indicar os cognatos falsos mais relevantes, os quais são indicados com a abreviação (FC)". Entre os exemplos dados, temos prevaricate, to $(F C)$ - "falar inconclusivamente; confundir"; e prevaricar (FC) - violate the law. Entretanto, um verbete não remete o usuário ao outro, nem mesmo há uma nota explicando qual é o falso cognato que corresponde ao referido verbete. O autor, talvez, espere que o usuário sozinho identifique prevaricate e prevaricar como falsos cognatos. Isso denota um sistema de remissivas inoperante.

A oitava subseção, "Organizações, associações e instrumentos financeiros", informa que "há verbetes para organizações internacionais e nacionais relevantes; associações empresariais; tipos de instrumentos financeiros; cláusulas comerciais; ou indices de bolsas de valores". Entretanto, constatamos que 
tais "verbetes" não estão apenas no corpo do dicionário, mas também na lista de abreviaturas. É o caso de "BOVESPA", por exemplo.

A lista de Abbreviations e "Abreviaturas" (páginas 1 a 6 e 7 a 14, respectivamente) é excessivamente longa e engloba não só as abreviaturas usadas na organização geral da obra - como, por exemplo, Loc. lat. para "locução latina" e Leg. para "legislação" -, mas também siglas e acrônimos como IR para "Imposto de Renda" e Jucerj para "Junta Comercial do Estado do Rio de Janeiro". Assim, tal lista não auxilia o manuseio do dicionário; muito pelo contrário, dificulta-o. Abaixo um excerto da lista Abbreviations em que a primeira e a terceira palavras são acrônimos; a segunda e a quinta, uma abreviatura; a quarta, uma sigla; e a última, uma abreviatura usada no paradigma informacional dos verbetes cuja entrada é um termo em português de Portugal.

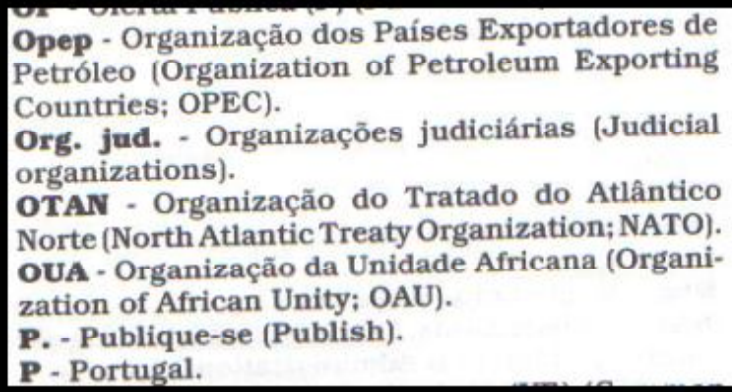

A nona subseção, "Expressões informais e gíria", alerta para o fato de tais unidades serem incluídas no dicionário e indicadas como "(informal)". Um exemplo curioso é "laranja (informal)", traduzido por nominee. Quando consultamos nominee, entretanto, não encontramos "laranja", mas "fiduciário, figura aparente; nomeado".

A subseção seguinte trata do "politicamente correto" e explica que expressões dessa natureza serão indicadas com (PC). O autor dá o exemplo de self-inflicted death $(P C)$ - "suicídio". Entretanto, em "suicídio", temos apenas "suicide; selfmurder", e não há, como nos outros casos, nenhuma referência que remeta o leitor a, nesse caso, uma forma "politicamente correta". 
Em último lugar, as duas últimas subseções - a 11, "Nomes patenteados e marcas registradas", e a 12, intitulada "Aviso" - não se referem, em absoluto, a como usar a obra, mas procuram isentar de responsabilidade o autor caso os verbetes de sua obra sejam usados de forma inadequada.

Encerramos aqui a primeira parte de nosso trabalho. Com o intuito de fazer um resumo dos aspectos macroestruturais das obras ora examinadas, elaboramos a tabela abaixo que ilustra essa primeira parte de nosso objetivo.

\begin{tabular}{|c|c|c|c|}
\hline \begin{tabular}{|l|} 
Aspectos \\
macroestruturais
\end{tabular} & CASTRO & MELLO & NORONHA \\
\hline $\begin{array}{l}\begin{array}{l}\text { Número de } \\
\text { termos }\end{array} \\
\end{array}$ & 1.500 & $\begin{array}{l}\text { Não consta (aprox. } \\
20 \text { mil) }\end{array}$ & $\begin{array}{l}40 \text { mil (inclui } \\
\text { palavras que não } \\
\text { pertencem à área de } \\
\text { especialidade) }\end{array}$ \\
\hline $\begin{array}{l}\text { Delimitação do } \\
\text { público-alvo }\end{array}$ & $\begin{array}{l}\text { Profissional e } \\
\text { estudantes de } \\
\text { Direito }\end{array}$ & $\begin{array}{l}\text { Não menciona. } \\
\text { Contudo menciona o } \\
\text { público leigo. }\end{array}$ & $\begin{array}{l}\text { Na Introdução } \\
\text { (profissionais legais } \\
\text { e empresários) }\end{array}$ \\
\hline Introdução & Em forma de "Nota" & $\begin{array}{l}\text { Em forma de "Ao } \\
\text { leitor" }\end{array}$ & Sim \\
\hline Guia do usuário & Não & Não & $\begin{array}{l}\text { Sim (inclui } \\
\text { informações não } \\
\text { aplicáveis ao } \\
\text { manuseio da obra) }\end{array}$ \\
\hline $\begin{array}{l}\text { Precisão } \\
\text { terminológica }\end{array}$ & $\begin{array}{l}\text { Não (e.g. } \\
\text { tradução/definição) }\end{array}$ & $\begin{array}{l}\text { Não (e.g. tradução/ } \\
\text { definição; } \\
\text { sinônimo/alternativa) }\end{array}$ & $\begin{array}{l}\text { Não (e.g. } \\
\text { abreviaturas/ siglas/ } \\
\text { acrônimos, } \\
\text { verbetes/entrada) }\end{array}$ \\
\hline \begin{tabular}{|l|} 
Lista de \\
abreviaturas
\end{tabular} & Não & $\begin{array}{l}\text { Sim (apesar de não } \\
\text { serem usadas no } \\
\text { paradigma } \\
\text { informacional) }\end{array}$ & $\begin{array}{l}\text { Sim (inclui siglas, } \\
\text { acrônimos e } \\
\text { abreviaturas usadas } \\
\text { no enunciado } \\
\text { lexicográfico) }\end{array}$ \\
\hline Bibliografia & $\begin{array}{l}\text { Não (menciona } 2 \\
\text { obras lexicográficas } \\
\text { na Nota) }\end{array}$ & $\begin{array}{l}\text { Sim (39 obras que } \\
\text { não refletem todo o } \\
\text { campo do Direito e } \\
\text { das quais } 14 \text { são } \\
\text { obras lexicográficas) }\end{array}$ & $\begin{array}{l}\text { Não (não há } \\
\text { nenhuma referência } \\
\text { ao corpus } \\
\text { consultado) }\end{array}$ \\
\hline Bidirecionalidade & Não aplicável & Não & Não \\
\hline $\begin{array}{l}\text { Apresentação } \\
\text { dos verbetes }\end{array}$ & Ordem alfabética & Ordem alfabética & Ordem alfabética \\
\hline \begin{tabular}{|l|} 
Uniformidade \\
\end{tabular} & Sim & Não & Não \\
\hline \begin{tabular}{|l|} 
Formatação da \\
entrada
\end{tabular} & Caixa-alta & Caixa-alta & Negrito \\
\hline \begin{tabular}{|l|} 
Escolha dos \\
verbetes
\end{tabular} & $\begin{array}{l}\text { Sem respaldo } \\
\text { científico }\end{array}$ & $\begin{array}{l}\text { Sem respaldo } \\
\text { científico (chega a } \\
\text { incluir palavras como } \\
\text { name, king etc.) }\end{array}$ & $\begin{array}{l}\text { Sem respaldo } \\
\text { científico (chega a } \\
\text { incluir palavras } \\
\text { como car, weather } \\
\text { etc.) }\end{array}$ \\
\hline
\end{tabular}


A partir de agora, passaremos à segunda parte de nosso objetivo e abordaremos a microestrutura das obras selecionadas à luz de dois binômios (wear and tear e null and void) de direito contratual nos dicionários de Castro, Mello e Noronha. Determinaremos a microestrutura desses verbetes, comparando-a com os modelos de microestrutura apresentados na Introdução, verificaremos o sistema de remissivas usado e, em seguida, faremos uma sugestão de um modelo de microestrutura tendo em mente o tradutor.

\section{A microestrutura dos dicionários juridicos bilingües: os binômios wear and tear e null and void}

O verbete para null and void se apresenta da seguinte forma em cada uma das obras analisadas, Castro, Mello e Noronha, respectivamente.

Como podemos ver, a estrutura dos verbetes é:
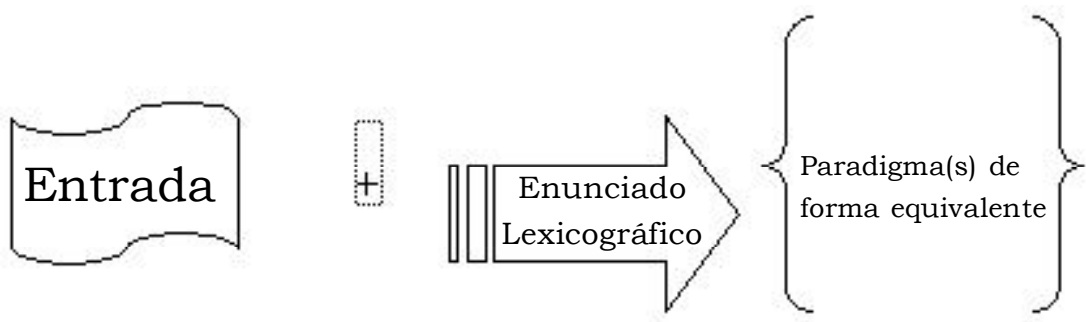

Se compararmos este modelo ao modelo usado no Dicionário de Direito Ambiental (Krieger et al., 1998), as diferenças entre a microestrutura das obras aqui analisadas na organização do verbete e na quantidade de informação dada ao usuário saltam aos olhos. Enquanto no Dicionário de Direito Ambiental (figura abaixo) temos paradigma informacional, paradigma de forma 
equivalente, paradigma definicional, paradigma pragmático e um sistema de remissivas, nos dicionários jurídicos em exame encontramos apenas um paradigma de forma equivalente, no caso dos binômios (em alguns verbetes, em vez do PFE, encontramos o PD).

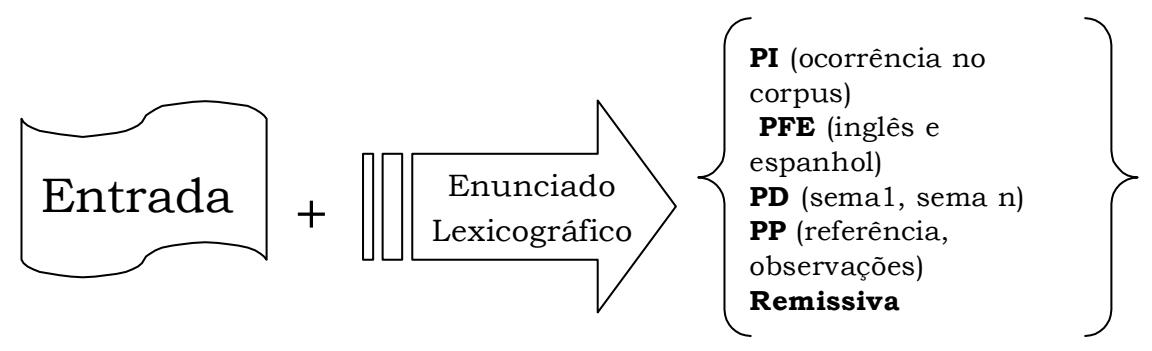

E mesmo os paradigmas de forma equivalente nas obras ora analisadas não satisfazem. Isto pode ser comprovado por uma simples consulta ao Google, em que null and void possui 325 mil ocorrências, sugerindo que se trata de unidade terminológica, mas "nulo e sem efeitos", paradigma de forma equivalente dado tanto em Castro quanto em Mello, possui apenas 18 ocorrências em textos traduzidos, e não em textos originalmente escritos em português. Em Mayoral Asensio (2003), podemos extrair que a tradução adequada para null and void não é uma expressão, mas apenas um termo: "nulo". O autor explica que alguns binômios em inglês são marcados pela redundância e, portanto, ao traduzir por "nulo" estamos preservando o conteúdo da mensagem.

No caso de wear and tear, nosso segundo binômio analisado nas três obras, temos, respectivamente:

Assim como em null and void, o enunciado lexicográfico de wear and tear possui apenas um paradigma de forma equivalente no enunciado lexicográfico do verbete; portanto, remetemos o leitor ao modelo desenhado para o primeiro binômio.

Procedemos à mesma pesquisa para esse binômio. No Google, constatamos 507 mil ocorrências em vários tipos de dis- 
curso. Para determinar sua ocorrência no discurso jurídico, pesquisamos wear and tear e agreement. Obtivemos 119 mil ocorrências, uma forte sugestão de que se trata de binômio usado nesta área de especialidade.

Entretanto, ao pesquisar "uso e desgaste", paradigma de forma equivalente em Noronha, encontramos apenas 121 ocorrências. Por outro lado, ao pesquisarmos "desgaste natural", paradigma de forma equivalente em Castro e Mello, obtivemos 4.060 ocorrências.

Como podemos ver, em ambos os casos, uma pesquisa baseada nos princípios da Lingüística de Corpus em que temos, até agora, apenas a freqüência do termo na internet, usando uma ferramenta simples como o Google, é possivel determinar se os paradigmas de forma equivalente fornecidos são realmente adequados. Nos casos dos binômios analisados, aqui resumimos os resultados na tabela abaixo:

\begin{tabular}{|l|c|c|c|}
\hline & CASTRO & MELLO & NORONHA \\
\hline null and void & PFE & PFE & PFE \\
wear and tear & inadequado & inadequado & inadequado \\
& PFE & PFE & PFE \\
& adequado & adequado & inadequado \\
\hline
\end{tabular}

Tanto em null and void, quanto em wear and tear as informações no enunciado lexicográfico se resumem a um paradigma de forma equivalente que, na maioria dos casos, provou conter um elemento inadequado, como pudemos verificar com o Google. Faremos agora, com o uso do programa WordSmith Tools uma pequena pesquisa com esses binômios para ver que mais a Lingüística de Corpus pode nos oferecer para que possamos fazer uma proposta de microestrutura para os binômios em questão.

A pesquisa será feita em meu corpus de pesquisa, que, ao tempo deste artigo, possuía cerca de 100 mil $^{10}$ palavras e era

10 Atualmente o corpus conta com, aproximadamente, 1 milhão de palavras. Parte do corpus faz parte do CorTec - Corpora Técnicos e está disponivel no site do Proje to COMET - Corpus Multilingüe para Ensino e Tradução http://www.fflch.usp.br/dlm/comet 
composto por contratos nominados e inominados ${ }^{11}$ em inglês e em português. O corpus divide-se em dois subcorpora: um comparável (documentos originais em ambas as línguas) e um paralelo (documentos originais em inglês com suas respectivas traduções para o português).

Para null and void e wear and tear, obtivemos as seguintes concordâncias com a ferramenta Concord:

$\mathrm{N}$ Concordance

1 respective terms or shall be declared to be null and void, or the validity hereof or thereof

2 is agreement shall become automatically null and void, and the license granted to the

3 delegation without such consent shall be null and void. The Guarantor confirms the

$\mathrm{N}$ Concordance

1 in good working order and condition, ordinary wear and tear except. So long as the Loan

$2 \mathrm{~d}$ condition as specified in the said Inventory (fair wear and tear and damage by the Insured

3 as at the commencement of the Tenancy (fair wear and tear and damage by the Insured

4 ace any parts which become defective due to fair wear and tear (except for light bulbs and

O reduzido número de concordâncias decorre do fato de meu corpus estar ainda pequeno e de termos contratos de várias naturezas. Entretanto, mesmo assim, veremos que será possivel extrair informações preciosas acerca dos binômios que não constam dos dicionários ora analisados.

Em null and void, por exemplo, podemos ver que, entre seus colocados, shall aparece em todas as linhas. Assim, ao elaborarmos uma microestrutura e optar por um paradigma pragmático, escolheríamos, certamente, um exemplo em que shall aparecesse. Além do mais, no paradigma informacional, inclui-

11 Ver arborescência. Anexo II. 
ríamos que se trata de um binômio que ocorre em diversos tipos de contrato.

Em wear and tear, por outro lado, entre seus colocados, registrariamos "fair" no paradigma pragmático. Além disso, indicariamos outros adjetivos que possivelmente ocorrem com o binômio. Um dado importante para o paradigma informacional é que o binômio ocorre, na maioria das vezes, em contratos de locação (tenancy agreements), fato que podemos observar através da nomenclatura dos arquivos fornecida pelo WordSmith Tools ao lado da respectiva linha de concordância.

Como se trata de um corpus pequeno, confirmamos o constatado no Google. A tabela abaixo sintetiza nossa pesquisa:

\begin{tabular}{|c|c|}
\hline Pesquisa no Google & $\begin{array}{l}\text { Número de } \\
\text { ocorrências }\end{array}$ \\
\hline "fair wear and tear" & 14.600 \\
\hline "fair wear and tear" tenancy & 2.010 \\
\hline "ordinary wear and tear" & 14.100 \\
\hline $\begin{array}{l}\text { "ordinary wear and tear" } \\
\text { tenancy }\end{array}$ & 2.500 \\
\hline "shall be null and void" & 42.200 \\
\hline $\begin{array}{l}\text { "shall be declared null and } \\
\text { void" }\end{array}$ & 1.900 \\
\hline $\begin{array}{l}\text { "shall be considered null and } \\
\text { void" }\end{array}$ & 2.920 \\
\hline $\begin{array}{l}\text { "shall be deemed null and } \\
\text { void" }\end{array}$ & 4.540 \\
\hline
\end{tabular}

Entre os colocados de null and void no corpus encontramos declared. Usando a intuição de tradutora para explorar a internet usando a ferramenta Google, encontramos vários outros, entre eles, considered e deemed. Em relação ao paradigma de forma equivalente, um corpus paralelo (originais + traduções) é excelente para produzir traduções prima facie, isto é, aquelas que auxiliarão o tradutor a escolher a melhor. Infelizmente, por nosso corpus não contar com contratos de locação traduzidos, não encontramos "desgaste natural" (PFE adequado para wear and tear). Por outro lado, felizmente não encontramos "nulo e sem efeitos" (PFE inadequado para null and void). 
As informações extraídas (com o WordSmith Tools) e as confirmadas (com o Google) com o auxílio das ferramentas da Lingüística de Corpus podem ser empregadas na elaboração dos paradigmas de um enunciado lexicográfico para um verbete de um vocabulário jurídico. É nossa próxima etapa.

Com o objetivo de elaborar um modelo de verbete que atenda às reais necessidades do tradutor técnico, um profissional que busca em obras terminográficas informações que o auxiliem não apenas na compreensão, mas essencialmente na produção de textos, elaboramos a microestrutura abaixo cujo ponto de partida foram os modelos de Barbosa e Krieger et al. Nossa sugestão de verbete é igual a:

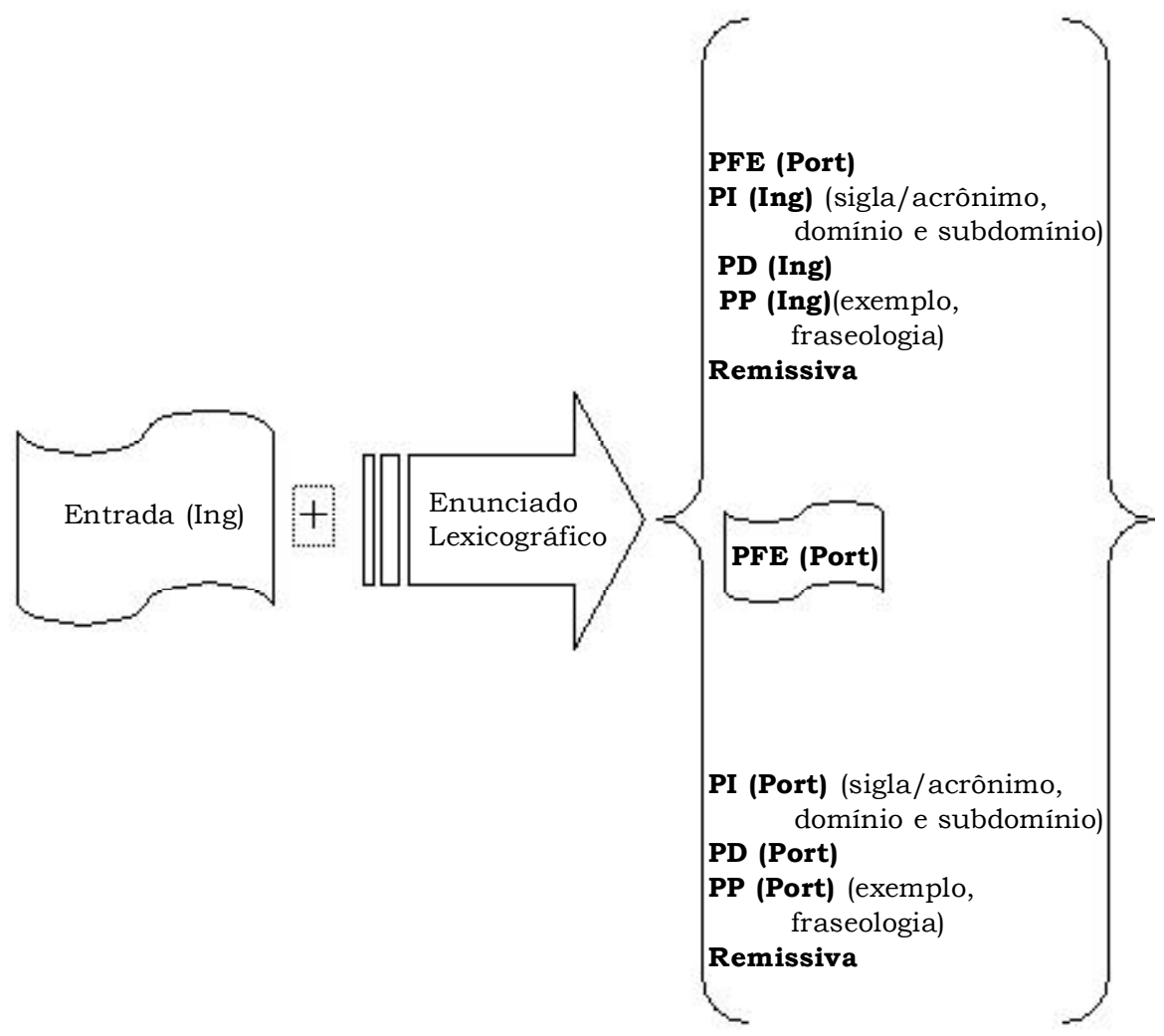


Em primeiro lugar, como podemos notar, trata-se de um verbete idealizado para um vocabulário bilíngüe na orientação inglês > português. Após a entrada, o primeiro paradigma é o de forma equivalente porque, como nosso público-alvo são os tradutores, a primeira coisa que buscam é a tradução e, só em caso de necessidade, consultam o restante do enunciado. Após o paradigma de forma equivalente, colocamos o informacional. Nele, gostaríamos de destacar a menção aos campos "domínio" e "subdomínio", pontos importantes em um vocabulário jurídico, pois há muitas unidades que são usadas apenas em certos ramos do Direito. É o caso do binômio wear and tear, cujo maior índice de ocorrência se dá nos contratos de locação. Assim, para esses dois campos constariam, respectivamente, "direito contratual" e "locação". O próximo paradigma, o definicional, incluiria definição do termo em inglês, pois, por se tratar de uma obra para tradutores, tal paradigma enriquece a obra em muito, possibilitando que o tradutor realize suas escolhas tendo em mente as duas culturas com as quais trabalha. Para produzir uma definição usando um corpus jurídico, acreditamos que isso não seria possivel com nosso corpus de contratos tal como se encontrava ao tempo deste trabalho, sendo necessário ampliá-lo, incluindo obras de doutrina, artigos acadêmicos etc., em que poderíamos encontrar um maior número de termos em contextos definicionais. Em seguida, temos o paradigma pragmático, que possibilitaria que o tradutor observasse a palavra dentro de um contexto, bem como identificasse a fraseologia em que ocorre. Nesse último caso, por exemplo, para wear and tear, incluiriamos: "fair/ natural/ordinary wear and tear" e outros exemplos encontrados com o auxílio da Lingüística de Corpus. Por fim, a primeira parte do enunciado é finalizada com uma remissiva.

$\mathrm{Na}$ segunda parte do enunciado repetimos o "paradigma de forma equivalente", fazendo com que ele assuma características de entrada e como tal tenha seu próprio enunciado lexicográfico exatamente igual ao da entrada principal, só que em português, e sem a presença, naturalmente, de um paradigma de forma equivalente. O paradigma informacional, por exemplo, ao trazer os campos de "domínio e subdomínio", possibilitará que o tradutor confronte os ramos do Direito na primeira parte do enun- 
ciado com o enunciado da forma equivalente. Assim, uma entrada como assault and battery e suas formas equivalentes "lesão corporal; ameaça" teriam os campos domínio e subdominio preenchidos de formas diferentes: tort law e tort e "direito penal; responsabilidade civil e crime contra a pessoa", respectivamente. Essas informações refletiriam as diferenças entre o nosso sistema jurídico (civil law) e o sistema jurídico anglo-americano (common law) que se desenvolveram e são organizados de maneiras bem distintas.

$\mathrm{O}$ paradigma definicional traria a definição do termo (PFE da entrada principal) em português, possibilitando que o tradutor, mais uma vez, cotejasse as sutilezas entre os sistemas. Após tal cotejamento, o tradutor encontraria mais um elemento que o auxiliaria a fazer a escolha certa se consultasse um paradigma pragmático com exemplo e fraseologia da área. Acreditamos que o paradigma pragmático seja o mais importante para o tradutor, pois “(...) uma adequada compreensão das linguagens de especialidade somente pode se dar a partir do entendimento de que os termos não existem em isolamento, nem derivam sua existência de um arcabouço lógico-conceptual, mas se manifestam, circulam e exercem sua função em situação, em uso efetivo" (Aubert, 2000).

Acreditamos que uma obra terminográfica organizada conforme nossa proposta de modelo proporcionaria ao tradutor técnico mais condições de realizar seu trabalho com segurança e qualidade.

Assim, para finalizar esta seção, propomos o modelo de verbete preenchido para um dos binômios apresentados: wear and tear. Os campos PFE, PI, e PP foram extraídos de nosso corpus e da internet, segundo elementos da Lingüística de Corpus. No campo PP, por exemplo, a "fraseologia" foi preenchida em ordem de freqüência da internet usando o Google e o campo "exemplo" com exemplo de nosso corpus. Só não usamos nossos próprios corpora para os campos PD em virtude de serem, como já mencionamos, composto apenas por contratos e não contar com doutrina sobre Direito Contratual, não proporcionando, portanto, concordâncias com contextos definicionais. Assim, a título provisório, para esses campos, extraímos a definição em 
inglês de Black e, em português, observamos perfunctoriamente as ocorrências do binômio em tela no Google e formulamos uma definição própria. Faz-se mister ressaltar que o modelo proposto foi completado provisoriamente, principalmente os campos dos paradigmas definicionais e o sistema de remissivas. O nosso verbete, portanto, seria:

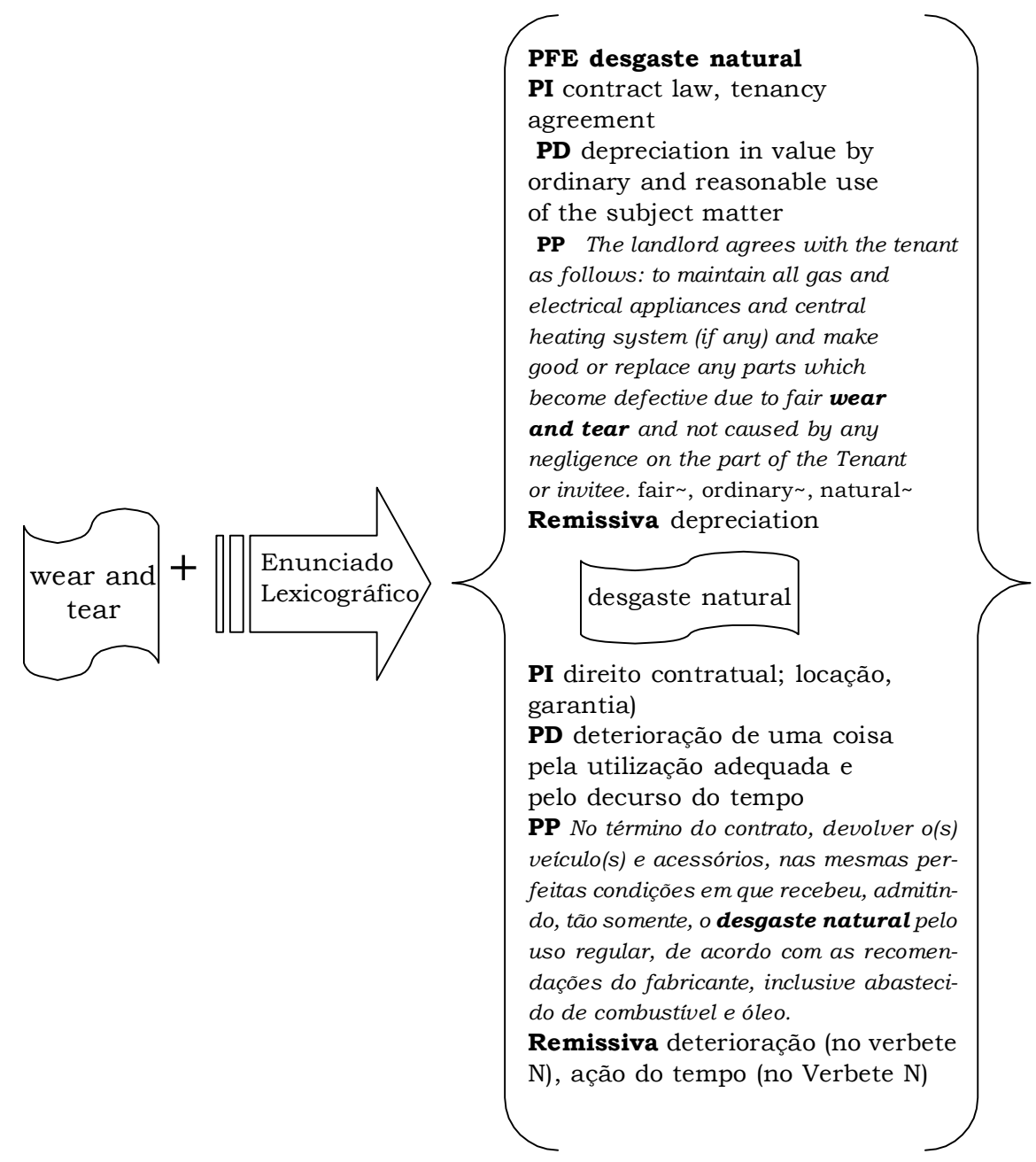

TradTerm, 12, 2006, p. 309-347 


\section{Considerações finais}

Acreditamos que, por meio deste breve estudo das obras intituladas dicionários jurídicos, seja possivel ao leitor conhecer um pouco do papel desempenhado por tais obras terminográficas em relação ao tradutor técnico, cujas necessidades, constatamos, não são totalmente atendidas. Entretanto, tal fato não ocorre apenas nas obras aqui estudas; há uma ausência generalizada, não apenas de dicionários, mas também de estudos descritivos do léxico e das linguagens técnicas para o tradutor especializado (Azenha, 1999).

Em virtude disso, nosso modelo de microestrutura para um verbete em obra terminográfica para tradutores leva em conta a afirmação de Borba (2003), segundo o qual "Um dicionário nunca deverá ser tomado apenas como um simples repositório ou acervo de palavras, ao contrário, deve ser um guia de uso e, como tal, tornar-se um instrumento pedagógico de primeira linha”. E, buscando a consecução do fim pedagógico (prática de ensinar), por meio de nosso modelo de microestrutura, visamos proporcionar ao tradutor um verbete que atendesse a suas necessidades e o ensinasse a fazer a melhor escolha.

Apesar de nosso estudo sugerir que as obras estudadas não atendem às necessidades dos tradutores técnicos, não podemos deixar de concordar com Mello em "Ao Leitor" ao citar que: "La vieja sabiduria advirtió que en derecho toda definición es peligrosa. Pero también hay en la vida muchas otras cosas que son peligrosas y que es menester usar o afrontar. Quein forjó el aforismo no pudo dejar de pensar, sin duda, que por muy peligrosa que sea una definición, mucho más peligroso es no tener ninguna definición. De los males, debe adoptar-se el menor" (Eduardo J. Couture apud Mello). 


\section{Referências bibliográficas}

MAYORAL ASENSIO, R. (2003) Translating official documents. Manchester \& Northampton: St. Jerome.

ATKINS, B.T.S. (1996) Bilingual dictionaries: past, present and future. In: GELlERSTAM, M. et al. (orgs.) Euralex 96 Proceedings. Gothenburg: Gothenburg University, Department of Sweedish.

AUBERT, F. H. (1996) Língua como estrutura e como fato histórico social: conseqüências para a terminologia. In: ALVES, I. M. (org.) $A$ constituição da normalização terminológica no Brasil. Cadernos de Terminologia. Vol I. São Paulo: FFLCH/CITRAT.

- (1996b) Introdução à metodologia da pesquisa terminológica bilíngüe. São Paulo: Humanitas/FFLCH-USP.

. (1984) Descrição e quantificação de dados em tradutologia. In: Tradução e Comunicação 2:2. São Paulo: Álamo.

- (2000) Tradução técnico-científica e terminologia: uma via de mão dupla. Acessado em 28/4/2003 in www.fflch.usp.br/citrat.

AZENHA JUNIOR, J. (1999) Tradução técnica e condicionantes culturais. Primeiros passos pra um estudo integrado. São Paulo: Humanitas.

BACELLAR, F. (2002) Elementos para a elaboração de um dicionário terminológico bilingüe em ciências agrárias. Tese de doutorado. São Paulo: FFLCH/USP.

BARBOSA, M. A. (1996) Dicionário, vocabulário, glossário: concepções. In: ALVES, I. M. (org.) A Constituição da normalização terminológica no Brasil. Cadernos de Terminologia. Vol. I. São Paulo: FFLCH/ CITRAT.

. (1989) Da microestrutura dos vocabulários técnico-científicos. Anais do IV Encontro Nacional da ANPOLL. Recife: ANPOLL.

. (2004) Lingüística de Corpus. São Paulo: Manole.

BERBER SARDINHA, T. (2002) Corpora eletrônicos na pesquisa em tradução. In: Tagnin, S.E.O. (org.) Cadernos de Tradução. Universidade Federal de Santa Catarina. Centro de Comunicação e Expressão. Núcleo de Tradução. N. ${ }^{\circ} 9$ (2002/1). Santa Catarina: NUT.

BORBA, F. da S. (2003) Organização de dicionários: uma introdução à lexicografia. São Paulo: Editora da UNESP.

BOWKER, L. \& PEARSON, J. (2002) Working with specialized language - A Practical Guide to Using Corpora. London and New York: Routledge. 
CABRÉ, M. T. (1999) La terminología representación y communicación y otros artículos. Barcelona: Institut Universitari de Lingüistica Aplicada - Universitat Pompeu Fabra.

COSERIU, E. (1980) Lições de lingüística geral. Trad. Evanildo Bechara. Rio de Janeiro: Ao Livro Técnico S.A.

FILLMORE. C. J. (1979) Innocence: a second idealization for linguistics. In: Berkely Linguistic Society 5, p. 63-76.

FROMM, G. (2002) Proposta para um modelo de glossário de informática para tradutores. Dissertação de Mestrado da Faculdade de Filosofia, Letras e Ciências Humanas da Universidade de São Paulo.

GOYOS JÚNIOR, D. de N. (1998) Noronha dicionário jurídico: inglêsportuguês. São Paulo: Observador Legal.

HAENSCH, G. et al. (1982) La lexicografia. Madrid: Espanha.

HUNSTON, S. (2002) Corpora in applied linguistics. Cambridge: Cambridge University Press.

KRIEGER, M. da G. et al. (1998) Dicionário de Direito - Terminologia das leis do meio ambiente. Porto Alegre: Editora da Universidade Federal do Rio Grande do Sul.

MELLO, M. C. de. (1998) Dicionário jurídico português-inglês. $7 .^{\text {a }}$ edição. Rio de Janeiro: Elfos.

MAILlOT, J. (1975) A tradução científica. Trad. Paulo Rónai. Brasília: UnB.

TAGNIN, S. E. O. (2002) Os corpora: instrumentos de auto-ajuda para o tradutor. In: Tagnin, S.E.O. (org.) Cadernos de Tradução. Universidade Federal de Santa Catarina. Centro de Comunicação e Expressão. Núcleo de Tradução. N. ${ }^{\circ} 9(2002 / 1)$. Santa Catarina: NUT. p. 191-220.

. (1989) Expressões idiomáticas e convencionais. São Paulo: Ática. VARANTOLA, K. (1994) The dictionary user as decision maker. In: Martin, W., W. Meijs, M. Moerland, E. ten Pas, P. van Sterkenburg \& P. Vossen (orgs.) Euralex 1994 Proceedings, Amsterdam: Vrije Universiteit Amsterdam. p. 606-611.

VILELA, M. (1995) Léxico e gramática. Coimbra: Livraria Almedina. 


\section{ANEXO 0}

Rol de binômios e polinômios identificados até o presente durante nossa pesquisa de mestrado.

Os binômios em negrito são os abordados no presente estudo.

\begin{tabular}{|c|c|}
\hline 1 - actual or threatened & 23 - lost or damaged \\
\hline 2 - acceptance and approval & $24-$ made and entered into by \\
\hline 3 - accepted and approved & 25 - neat and tidy \\
\hline 4 - agrees and covenants & 26 - null and void \\
\hline 5 - at law or equity & 27 - organized and existing \\
\hline 6 - business and concerns & under \\
\hline 7 - claim or judgment & 28 - pay and indemnify \\
\hline 8 - clean and tidy & 29 - possess and enjoy \\
\hline 9 - covenants and agrees & 30 - right of action or remedy \\
\hline 10 - destroyed or damaged & 31 - right, power or privilege \\
\hline 11 - fair wear and tear & 32 - rights and obligations \\
\hline 12 - final and binding & 33 - rights or remedies \\
\hline 13 - freedom and liberty & 34 - governed and interpreted \\
\hline 14 - full faith and credit & 35 - rules and regulations \\
\hline 15 - full force and effect & 36 - sale and purchase/purchase \\
\hline 16 - governed by and & and sale \\
\hline construed in & 37 - sole and only employer \\
\hline 17 - health and safety & 38 - solely and fully liable \\
\hline 18 - hold and enjoy & 39 - understand and acknowledge \\
\hline 19 - in whole or in part & 40 - understood and agreed \\
\hline 20 - incurred of suffered & 41 - unless and until \\
\hline 21 - joint and several & $42-$ liens and claims \\
\hline 22 - jointly and severally liable & 43 - wear and tear \\
\hline
\end{tabular}




\section{ANEXO I}

\section{Dicionários usados e/ou citados neste artigo}

BLACK, Henry Campbell. Black's Law Dictionary. 6a. edição. St. Paul, Minn.: West Publishing, CO., 1990.

CASTRO, Flávio de. Compacto Dicionário Jurídico: inglês-português. Rio de Janeiro: Editora Aide, 1994.

KRIEGER, Maria da Graça; MACIEL, Anna Maria Becker; ROCHA, João Carlos de Carvalho; FINATTO, Maria José Bocorny; BEVILACQUA, Cleci Regina. Dicionário de Direito Ambiental: Terminologia das leis do meio ambiente. [S.1.]: Editora da UFRGS, 1998.

GOYOS JR; Durval de Noronha. Dicionário Jurídico: inglês-português/ português-inglês. $3{ }^{a}$ edição revisada e ampliada. São Paulo: Editora Observador Legal, 1998.

MELLO, Maria Chaves de. Dicionário Jurídico: inglês-português/português-inglês.7. ${ }^{a}$ Edição. Rio de Janeiro: Editora Elfos, 1998.

FERREIRA, Aurélio Buarque de Holanda. Novo Aurélio: O Dicionário da Língua Portuguesa. $3 .^{a}$ edição. Rio de Janeiro: Editora Nova Fronteira, 1999. 


\section{ANEXO II}

Arborescência da área do Direito Contratual.

As cores indicam a categoria de textos que constituem nosso corpus de pesquisa.

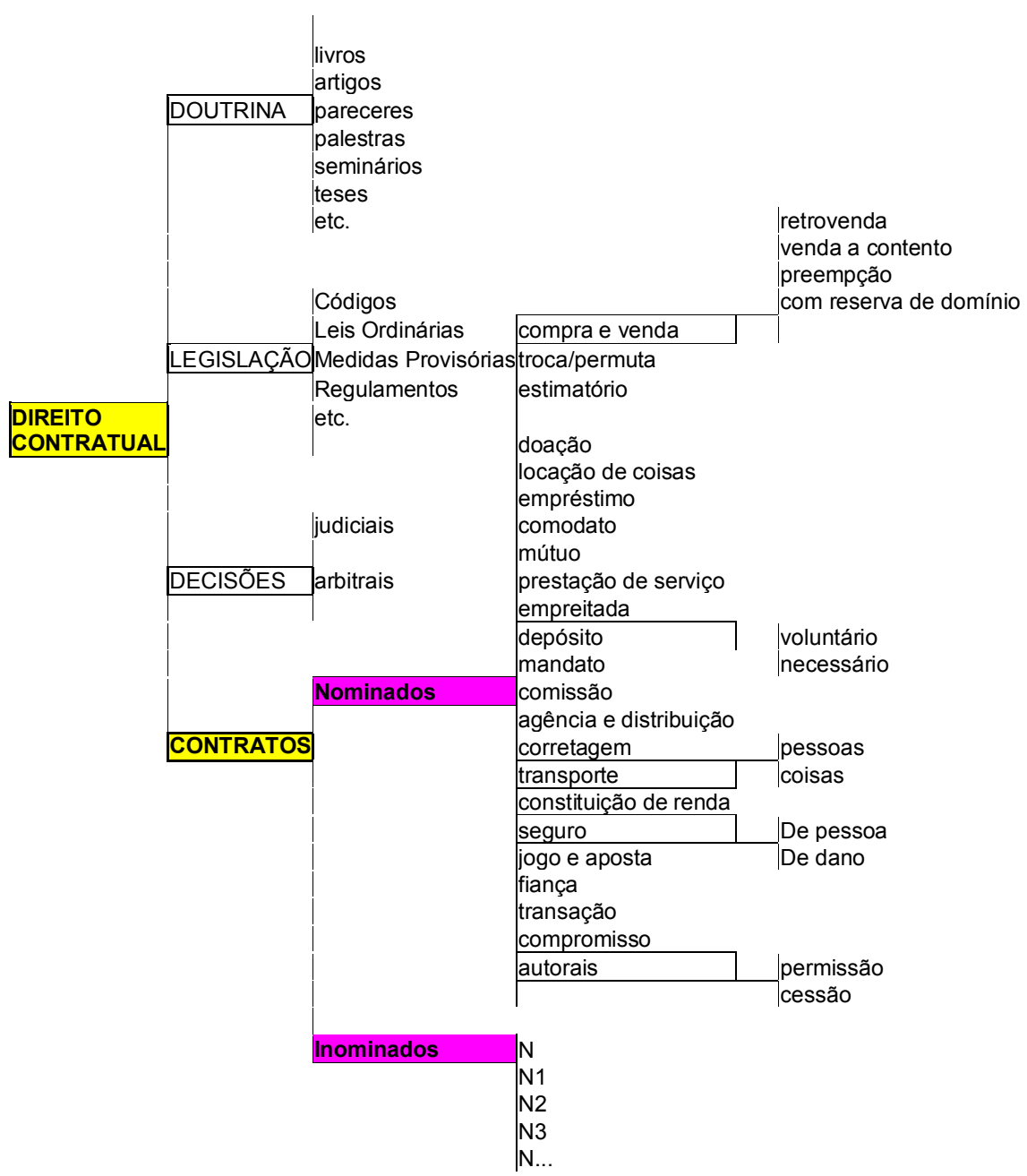

TradTerm, 12, 2006, p. 309-347 


\section{ANEXO III}

\begin{tabular}{|c|c|c|}
\hline \multicolumn{2}{|c|}{ Entrada do dicionário MELLO (1998) } & \multirow{3}{*}{$\begin{array}{l}\text { Nossos comentários } \\
\text { Não são binômios, mas } \\
\text { sintagmas nominais com } \\
\text { prováveis binômios em seu } \\
\text { corpo. Consultamos a referida } \\
\text { obra em busca dos binômios, } \\
\text { mas não há entradas para eles. }\end{array}$} \\
\hline $\begin{array}{l}\text { Action for money } \\
\text { had and received' }\end{array}$ & $\begin{array}{l}\text { Ação judicial para entrega } \\
\text { de um valor injustamente } \\
\text { retido. }\end{array}$ & \\
\hline $\begin{array}{l}\text { Building and loan } \\
\text { association }\end{array}$ & $\begin{array}{l}\text { Associação de crédito e } \\
\text { poupança (destinada ao } \\
\text { financiamento da } \\
\text { construção de imóveis). }\end{array}$ & \\
\hline Baron et feme [sic] & Marido e mulher. & $\begin{array}{l}\text { Este é o primeiro binômio que } \\
\text { surge, entretanto, não está em } \\
\text { inglês. A autora também não } \\
\text { fornece o contexto em que se } \\
\text { usa (e.g. ramo do Direito, tipo de } \\
\text { documentos etc.). }\end{array}$ \\
\hline Bed and board & $\begin{array}{l}\text { Cama e mesa (separação } \\
\text { de corpos). }\end{array}$ & $\begin{array}{l}\text { A autora oferece, em primeiro } \\
\text { lugar, uma tradução literal, que } \\
\text { não é usada em nosso direito. } \\
\text { Em seguida, oferece o que } \\
\text { acredita ser uma } \\
\text { correspondência, mais uma vez } \\
\text { sem contexto. }\end{array}$ \\
\hline C.\&F. & $\begin{array}{l}\text { abr. 'Cost and freight' } \\
\text { (cláusula contratual } \\
\text { indicando que o preço dado } \\
\text { inclui custo e frete até o } \\
\text { destino citado) }\end{array}$ & $\begin{array}{l}\text { A autora inclui, nas entradas, } \\
\text { siglas das INCOTERMS } \\
\text { (International Rules for } \\
\text { Interpretation of Trade Terms), } \\
\text { de 1990, apresenta a definição }\end{array}$ \\
\hline C.F. & $\begin{array}{l}\text { abr. 'Cost and freight } \\
\text { (cláusula contratual } \\
\text { indicando que o preço } \\
\text { citado inclui custo e frete } \\
\text { até o destino) }\end{array}$ & $\begin{array}{l}\text { sem, entretanto, fornecer os } \\
\text { correspondentes em português. } \\
\text { Em português, as abreviaturas } \\
\text { são mantidas na linguagem do } \\
\text { comércio internacional. Assim, }\end{array}$ \\
\hline C.F.I. & $\begin{array}{l}\text { abr. 'Cost, freight and } \\
\text { insurance' (o mesmo que } \\
\text { C\&F). }\end{array}$ & $\begin{array}{l}\text { apesar de não se traduzirem, } \\
\text { deveriam constar da entrada. }\end{array}$ \\
\hline Cost and freight & Custo e frete & $\begin{array}{l}\text { Aqui a autora agiu } \\
\text { acertadamente, apesar de não } \\
\text { fornecer o contexto. }\end{array}$ \\
\hline $\begin{array}{l}\text { Checks and } \\
\text { balances }\end{array}$ & Freios e contrapesos & $\begin{array}{l}\text { Aqui a autora também agiu } \\
\text { acertadamente, apesar de não } \\
\text { fornecer o contexto. }\end{array}$ \\
\hline Claim and delivery & $\begin{array}{l}\text { Ação judicial de } \\
\text { reivindicação de bem } \\
\text { móvel. }\end{array}$ & $\begin{array}{l}\text { A autora apenas explica o } \\
\text { binômio sem apresentar uma } \\
\text { correspondência que, a princípio } \\
\text { poderia ser: (ação de) busca e } \\
\text { apreensão. }\end{array}$ \\
\hline
\end{tabular}

